\title{
Pedotransfer in soil physics: trends and outlook - A review -
}

\author{
${ }^{1}$ YA. PACHEPSKY, ${ }^{2}$ K. RAJKAI and ${ }^{3}$ B. TÓTH \\ ${ }^{1}$ USDA-ARS Environmental Microbial and Food Safety Laboratory. Beltsville, MD \\ 20705; ${ }^{2}$ Department of Soil Science. Institute for Soil Science and Agricultural Chemis- \\ try, Centre for Agricultural Research, Budapest and ${ }^{3}$ Department of Crop Production \\ and Soil Science, Georgikon Faculty, University of Pannonia, Keszthely
}

\begin{abstract}
Parameters governing the retention and movement of water and chemicals in soils are notorious for the difficulties and high labor costs involved in measuring them. Often, there is a need to resort to estimating these parameters from other, more readily available data, using pedotransfer relationships.

This work is a mini-review that focuses on trends in pedotransfer development across the World, and considers trends regarding data that are in demand, data we have, and methods to build pedotransfer relationships. Recent hot topics are addressed, including estimating the spatial variability of water contents and soil hydraulic properties, which is needed in sensitivity analysis, evaluation of the model performance, multimodel simulations, data assimilation from soil sensor networks and upscaling using Monte Carlo simulations. Ensembles of pedotransfer functions and temporal stability derived from "big data" as a source of soil parameter variability are also described.

Estimating parameter correlation is advocated as the pathway to the improvement of synthetic datasets. Upscaling of pedotransfer relationships is demonstrated for saturated hydraulic conductivity. Pedotransfer at coarse scales requires a different type of input variables as compared with fine scales. Accuracy, reliability, and utility have to be estimated independently. Persistent knowledge gaps in pedotransfer development are outlined, which are related to regional soil degradation, seasonal changes in pedotransfer inputs and outputs, spatial correlations in soil hydraulic properties, and overland flow parameter estimation.

Pedotransfer research is an integral part of addressing grand challenges of the twenty-first century, including carbon stock assessments and forecasts, climate change and related hydrological weather extreme event predictions, and deciphering and managing ecosystem services.
\end{abstract}

Correspondence to: YAKOV PACHEPSKY, USDA-ARS Environmental Microbial and Food Safety Laboratory, 10300 Baltimore Ave, Bldg. 173, Beltsville, MD 20705. USA.

E-mail:Yakov.pachepsky@ars.usda.gov 
Overall, pedotransfer functions currently serve as an essential instrument in the science-based toolbox for diagnostics, monitoring, predictions, and management of the changing Earth and soil as a life-supporting Earth system.

\section{Introduction}

Parameters governing the retention and movement of water and chemicals in soils are notorious for the difficulties and high labor costs involved in measuring them. Often, there is a need to resort to estimating these parameters from other, more readily available data. Following BRIGGS and SHANTZ (1912), who were the pioneers in the field, generations of researchers quantified and interpreted relationships between soil properties. Such terms as "prediction of" or "predicting" soil properties, "estimation of" or "estimating" soil properties, "correlation of" or "correlating" soil properties, were used interchangeably to name the contents, procedures and results of these types of studies (CARTER \& BENTLEY, 1991; RAWLS et al., 1991; VAN GenUChTEN \& LeiJ, 1992; Timlin et al., 1996; MCBRATNEY et al., 2002).

Relatively recently, equations expressing relationships between soil properties were proposed to be called "transfer functions" (BOUMA \& VAN LANEN, 1987) and later "pedotransfer function"' or PTFs (BouMA, 1989) and also the term "pedotransfer rule" (PTR) was introduced (BATJES, 1996) and used (DAROUSSIN \& KING, 1996). Large international databases, such as UNSODA (LeIJ, 1996), HYPRES (WÖSTEN et al.,1999), WISE (BATJES, 1996), the NRCS National Soils Information System (RAWLS et al., 2007), EU-HYDI (WEYNANTS et al., 2013), as well as smaller national databases such as the Hungarian Detailed Soil Hydrophysical Database (MARTHA) (MAKÓ et al., 2010) were established and used for the purpose of PTF development. Recently the number of PTF applications has increased significantly due to the development of GIS-based regional modeling. According to the SCOPUS database, more than $55 \%$ of all pedotransfer papers were published in 2009-2015.

Pedotransfer functions to predict soil hydraulic properties are most numerous (PACHEPSKY \& RAWLS, 2004). Such PTFs have many potential user groups. For example, soil water retention and hydraulic conductivity data are needed to partition precipitation into runoff and infiltration, to assess evapotranspiration, to schedule management practices, especially irrigation and chemical application, to establish components of the heat balance, and to predict contaminant transport. Pedotransfer relationships are being developed for biogeochemical soil parameters. Research on global change relies on pedotransfer in many its components.

PTFs package knowledge and data that are used for multiple applications of soil research in environmental science and engineering such as soil water flow modeling (DENG et al., 2009; PAN et al., 2012; СichOTA et al., 2013), predictive soil mapping (DAI et al., 2013; UGBAJE \& REUTER, 2013; WERBAN et al., 2013) or filling gaps in soil datasets (NEMES et al., 2010). 
The applied purpose of PTF development does not, however, eliminate the basic and methodological questions about PTF. Why do pedotransfer relationships exist? Is there a knowledge other than just soil attribute values (soil classification being an example) leading to improvements in PTF accuracy and reliability? How to access the reliability of PTFs? Is there a limit of accuracy and reliability of PTFs and what does it depend on? What defines the relative importance of PTF inputs? What is the effect of scale on PTFs? How to evaluate the quality of PTF inputs and outputs? Answering basic questions is necessary to assure the best use of available data and the best feasible quality of PTFs in terms of accuracy, reliability, and utility.

This work is a mini-review that focuses on trends in pedotransfer development across the World and does not cover the subject in depth. Pedotransfer has been defined as the conversion of data we have to data we need (WÖSTEN et al., 2001), and this review will consider trends regarding data that are in demand, data we have, and methods to build pedotransfer relationships.

\section{Estimating spatial variability of water contents and soil hydraulic properties}

Estimating spatial variability becomes a must in many applications of soil modeling. Fig. 1 illustrates the critical need in variability estimation in several types of soil modeling activities. The sensitivity of a model to hydraulic properties requires knowledge of the variability of these properties. Evaluation of model performance should rely on comparison of uncertainties in data and uncertainties in model predictions (Fig. 1a). A model should not be more accurate than the data which is supposed to be reproduced (DENG et al., 2009). Another use of variability of soil properties consists in using multimodel simulations (Fig. 1b). Calibration of variably saturated flow models with field monitoring data is complicated by the strongly non-linear dependency of unsaturated flow parameters on water content. Combining predictions using various independent models, often called multimodel prediction, is becoming a popular modeling technique (e.g. LIAO et al., 2014).

The example in Fig. 1b shows the results of solving the Richards flow equation using HYDRUS-1D with 19 plausible soil hydraulic parameter sets (GUBER et al., 2005). Yet another use of variability information can be found in data assimilation from soil sensor networks (Fig. 1c). Soil water flow models are necessarily based on simplified assumptions about the mechanisms, processes, and parameters of water retention and flow, which causes errors in soil water flow model predictions. Data assimilation (DA) with the ensemble Kalman filter (EnKF) corrects modeling results based on measured state variables, information on uncertainty in measurement results and uncertainty in modeling results. The need to know the uncertainty of measurement results calls for finding water content variability estimates.

Finally, knowing the variability of soil hydraulic parameters is a precondition for upscaling using Monte Carlo simulations (e.g. ARORA et al., 2015). Such upscaling includes either multiple simulations at the fine scale and then averaging 
results ("modeling-to-averaging" yellow trajectory in Fig. 1d) or averaging of hydraulic properties followed by simulations with averaged parameters ("averagingto-modeling" orange trajectory in Fig. 1d). Knowing variability is a must for both the yellow and oranges trajectories.

Two methods were proposed to estimate the variability of soil hydraulic properties at an arbitrary site. One method relies on PTFs developed at other sites, and another method calls for using "big data" that have become available recently.

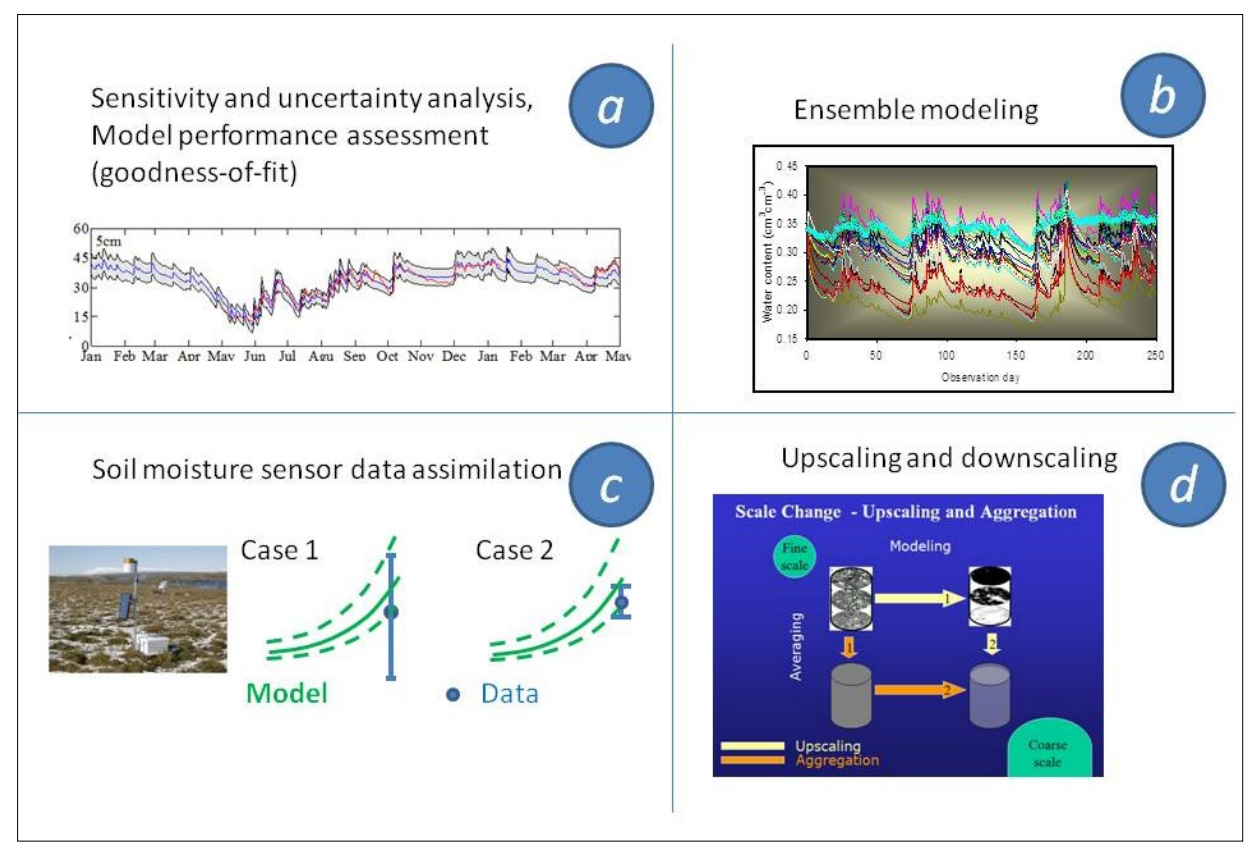

Fig. 1

Uses of data on variability of soil hydraulic property and soil water contents.

Notes: (a) evaluation of model calibration results (from QU et al. (2014); (b) ensemble modeling of soil water contents (after GUBER et al., 2009); (c) update of soil water flow modeling results for two cases of relative difference between uncertainty in modeling results and uncertainty in measurement results; the update brings soil water contents much closer to the average measured values if the uncertainty in measured values is less than the uncertainty in simulation results; (d) two possible uses of data on variability in hydraulic properties in upscaling soil water flow; multiple simulations with subsequent averaging of results or averaging of multiple parameter sets and subsequent simulation

\section{Using PTFs developed at other sites to estimate variability}

The reliability of PTFs outside the site of their development is essentially unknown. This, however, does not preclude using PTFs developed at various other sites to represent possible variability within a single site. 


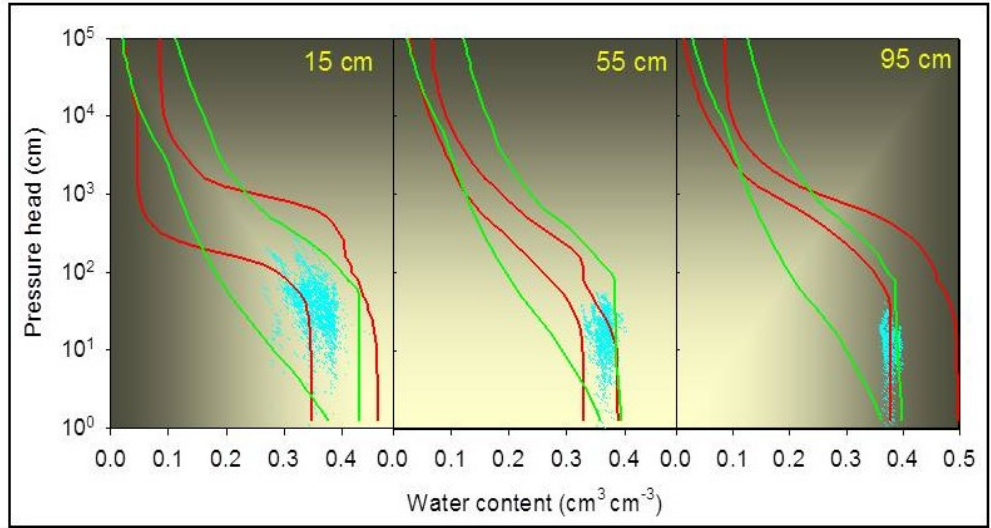

Fig. 2

Measured and estimated soil water retention of a loamy soil.

Notes: field measurements; 95\% tolerance interval of laboratory water retention; $\quad 95 \%$ tolerance interval of ensemble-estimated water retention

Fig. 2 presents an example of using 19 soil water retention PTFs to represent the water retention of a loam soil for a trench in Belgium. The PTF calculator can be found at the website http://www.ars.usda.gov/Research/docs.htm?docid=21211. The soil water retention variability envelope for water retention measured in the field was represented by PTFs much better than by the laboratory water retention measurements (PACHEPSKY et al., 2011).

When variability estimates are used to generate ensembles of models, finding the best way of combining predictions from individual models remains a topic of research. GUBER et al. (2009) compared different methods of combining the simulation results from 19 individual models by (i) using only the best model, (ii) using equal weights, (iii) regressing measured values to the results of the individual models, (iv) using singular-value decomposition (SVD) in the regression, (v) using Bayesian model averaging, and (vi) using weights derived from the Akaike Information Criterion. The SVD multimodel was the best method, with an accuracy of about $0.01 \mathrm{~m}^{3} \cdot \mathrm{m}^{-3}$ at the $35 \mathrm{~cm}$ depth and about $0.005 \mathrm{~m}^{3} \cdot \mathrm{m}^{-3}$ at greater depths for 30 days of monitoring and 13 months of testing. Nevertheless, Bayesian averaging continues to be popular (WANG et al., 2015).

Data assimilation with variability estimates from PTFs was demonstrated by PAN et al. (2012), who generated an ensemble of Richards' equation-based models for the EnKF application to the assimilation of soil water content data. They researched how effective the assimilation of soil moisture sensor data can be in correcting simulated soil water content profiles in a field soil. Data from a field experiment were used, in which 60 two-rod time domain reflectometry (TDR) probes were installed in a loamy soil at five depths to monitor the soil water content.

An ensemble of models was developed with six PTFs for water retention and four PTFs for the saturated hydraulic conductivity (Ksat). Measurements at all five 
depths and at one or two depths were assimilated. Accounting for the temporal stability of water contents substantially decreased the estimated noise in the data. Applicability of the Richards' equation was confirmed by the satisfactory calibration results. In the absence of calibration and data assimilation, simulations developed a strong bias caused by the overestimation of Ksat from PTFs. Assimilating measurements from a single depth of $15 \mathrm{~cm}$ or $35 \mathrm{~cm}$ provided substantial improvements at all other observation depths. An increase in data assimilation frequency improved model performance between the assimilation times. Overall, bringing together developments in pedotransfer functions, including the temporal stability of soil water patterns - the mean relative differences of soil water content -, and soil water content sensors has a potential to create a new source of data to improve modeling results in soil hydrology and related fields.

\section{"Big data" and spatial variability patterns in soil hydrology}

The advent of geophysical methods, proximal soil sensing, and sensor networks substantially changed the landscape of PTF development by making available millions of measurements at a reasonably low cost (e.g. BABAEIAN et al., 2015). Most of such "big data" do not provide direct measurements of soil variables that are of interest in pedotransfer work (soil water contents at desirable ranges of depths, soil water retention, and soil hydraulic conductivity).

Spatio-temporal variations of soil water contents from sensor networks may serve as a potential source of data on the spatial variation of soil hydraulic properties. This was demonstrated by MARTINEZ et al. (2013), who simulated onedimensional water flow with the HYDRUS code for bare and grassed sandy loam, loam and clay soils at different levels of variability in the saturated hydraulic conductivity $\mathrm{K}_{\text {sat }}$. Soil water content at 0.05 and $0.60 \mathrm{~m}$ and the average water content of the top $1 \mathrm{~m}$ were analyzed. Results were presented using the metric of soil water temporal stability in 100 soil columns used for each combination of soil and season. Using log-normal distributions of $\mathrm{K}_{\text {sat }}$ resulted in mean relative differences distributions that were commonly observed in experimental studies of soil water content variability. Linear relationships were observed between the scaling factor of $\ln \mathrm{K}_{\text {sat }}$ and the spread of the mean relative differences distributions. Variation in mean relative differences was higher in coarser textures than in finer ones and more variability was seen in the topsoil than in the subsoil. Root water uptake decreased the mean relative differences variability in the root zone and increased the variability below it. Water flow simulations indicated the possibility of estimating the spatial variability of $\mathrm{K}_{\mathrm{sat}}$ from soil water content monitoring with a sensor network.

Spatial variability in soil water contents can be derived from temporal variability. MARTINEZ et al. (2012) tested the hypothesis that regression relationships between soil water content $(\theta)$ and collocated apparent electrical conductivity $\left(\mathrm{EC}_{\mathrm{a}}\right)$ can become more accurate if several time-lapse $\mathrm{EC}_{\mathrm{a}}$ surveys rather than a single $\mathrm{EC}_{\mathrm{a}}$ survey are used. Vertisol plots under conventional tillage and direct drilling were surveyed for gravimetric $\theta\left(\theta_{\mathrm{g}}\right)$ in the top $0.3 \mathrm{~m}$ layer at 17 times and for topsoil $\mathrm{EC}_{\mathrm{a}}$ at 13 times in 2008 through 2010. Only weak correlations (with $\mathrm{R}<0.21$ ) 
were found between $\mathrm{EC}_{\mathrm{a}}$ and $\theta_{\mathrm{g}}$ measured on the same day. The accuracy of regression predictions of $\theta$ substantially improved when data of several $\mathrm{EC}_{\mathrm{a}}$ surveys, rather than a single survey, were used. Therefore, knowledge about the temporal variability in soil properties, as captured by the time-lapse $\mathrm{EC}_{\mathrm{a}}$ data, improved the estimation of spatial variability of soil water contents without determining soil properties that affect soil-water content.

\section{Estimating parameter correlation}

Statistical distributions of soil hydraulic parameters have to be known in the generation of synthetic fields of soil hydraulic properties used in ensemble modeling of soil water dynamics and soil water content data assimilation. Pedotransfer functions that provide statistical distributions of water retention and hydraulic conductivity parameters for textural classes are most often used in parameter field generation. The presence of strong correlations can substantially influence the parameter generation results. QU et al. (2015) found that assuming correlations between parameters of the van Genuchten-Mualem (VGM) equation strongly affects the results of inverse modeling, and makes these results more interpretable.

The most commonly used set of functions to describe soil hydraulic properties include the van Genuchten equation for water retention (VAN GENUCHTEN, 1980):

$$
S_{e}=\frac{\theta(h)-\theta_{r}}{\theta_{s}-\theta_{r}}=\left[1+(\alpha h)^{n}\right]^{1-1 / n}
$$

Eq (1) coupled with the MUALEM model (1976) describing the hydraulic conductivity curve:

$$
K\left(S_{e}\right)=K_{0}\left\{S^{l}\left[1-\left(1-S_{e}{ }^{n /(n-1)}\right)^{1-1 / n}\right]^{2}\right\}
$$

where $S_{e}$ is effective saturation (dimensionless); $\theta(h)$ is water retention at given $h$ pressure head (cm of water column), $h$ is considered here to be positive under unsaturated conditions, $\theta_{r}$ and $\theta_{s}$ are the residual and saturated moisture content $\left(\mathrm{cm}^{3} \cdot \mathrm{cm}^{-3}\right), \alpha$ is a parameter corresponding approximately to the inverse of the air-entry value $\left(\mathrm{cm}^{-1}\right)$, and $n$ is a shape parameter (dimensionless)

Parameter $l$ is a shape parameter (dimensionless) which is usually assumed to be close to -0.5 , although in reality it may vary from -10 to 10 and beyond. $K\left(S_{e}\right)$ is the soil hydraulic conductivity $\left(\mathrm{cm} \cdot \mathrm{day}^{-1}\right)$ at given saturation and $K_{0}$ is the hydraulic conductivity acting as a matching point at saturation $\left(\mathrm{cm} \cdot \mathrm{day}^{-1}\right)$. Thus, correlations have to be established between parameters $\theta_{r}, \theta_{s}, \alpha, n, l$ and $K_{0}$. So far two differrent approaches have been developed to estimate these correlations.

The first approach uses pedotransfer functions to generate VGM parameters for a large number of soil compositions within a textural class, and then computes parameter correlations for each of the textural classes. The second approach computes 
the VGM parameter correlations directly from parameter values obtained by fitting the VGM model to the water retention and hydraulic conductivity of soil samples belonging to a textural class. CARSEL and PARISH (1988) used the RAWLS et al. (1982) pedotransfer functions, and FAULKNER et al. (2003) used the Rosetta pedotransfer algorithm (SCHAAP et al., 2001) to develop correlations according to the first approach. The second approach was applied with the UNSODA database (NEMES et al., 2001), the US Southern Plains database (TimLIN et al., 1999), and the Belgian database (VEREECKEN et al., 1989, 1990). A substantial number of considerable $(>0.7)$ correlation coefficients were found. Large differences were encountered between parameter correlations obtained with different approaches and differrent databases for the same textural classes (FAULKNER et al., 2003). The first of the two approaches generally resulted in higher values of correlation coefficients between VGM parameters. One feature of this approach is that results depend on pedotransfer relationships not only within a given textural class but also on pedotransfer relationships within other textural classes, since the pedotransfer relationships are developed across the database containing data for several textural classes. Therefore, joint multivariate parameter distributions for a specific class may not be sufficiently accurate if developed with the first approach.

\section{Pedotransfer and scale}

The need for $\mathrm{K}_{\text {sat }}$ and water retention values at different scales is related to the suggestion to match the scale of measurement with the scale of model resolution (NEUMAN \& WiERENGA, 2003). The latter is defined by the size of computational grid cells, which may be quite large in field projects. The overwhelming majority of data on soil hydraulic properties is obtained on relatively small samples with diameters and heights between 5 and $10 \mathrm{~cm}$. Computational cells in realistic modeling projects can be of several meters. Therefore, the use of pedotransfer to estimate hydraulic properties has to be accompanied by a scaling relationship.

\section{Upscaling pedotransfer results}

Both saturated hydraulic conductivity and soil water retention were shown to depend on the support area or volume. Some dependencies of $\mathrm{K}_{\text {sat }}$ on the support area are shown in Fig. 3. As the characteristic support size increases, $K_{\text {sat }}$ values first increase by one to two orders of magnitude and then stabilize. Data in the range of scales where $K_{\text {sat }}$ increases are rarely available, and it is usually assumed that the increase is $\log$ linear, i.e. $\mathrm{K}_{\text {sat }}$ increases with test volume, area, or radius according to a power law. 


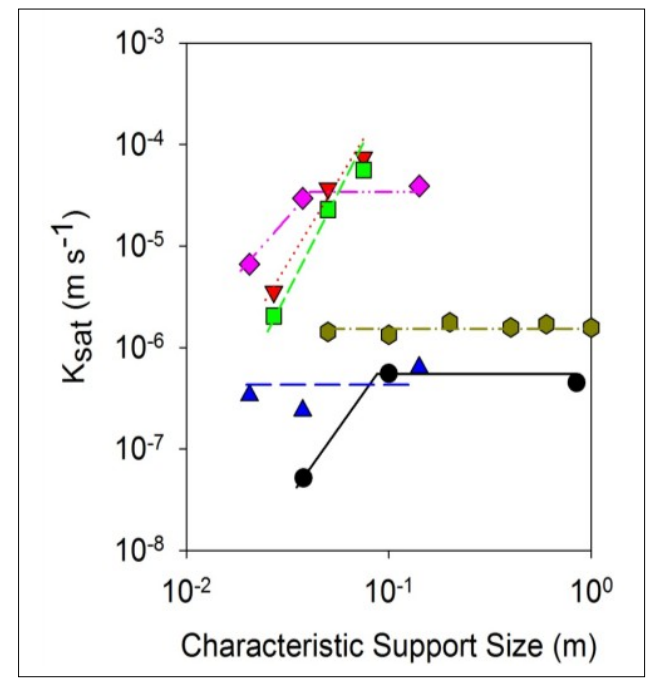

Fig. 3

Dependencies of measured saturated hydraulic conductivity on test radius in soils

Notes: quartz-diorite saprolite at $200 \mathrm{~cm}$ depth, loamy texture $-\mathrm{K}_{\mathrm{sat}}$ measurements on cores, soil columns, and drainfield (VEPRASKAS \& WILLIAMS, 1995); V Groseclose soil, Ap horizon, loam and $\square$ Groseclose Bt clay cores of three sizes (KoOL et al. 1986);

Kokomo soil, mixed mineralogy silty clay loam at $50 \mathrm{~cm}$, and $\boldsymbol{\Delta}$-Hoytville illitic clay from $23 \mathrm{~cm}-\mathrm{K}_{\mathrm{sat}}$ measurements with permeameter, on soil cores, and soil blocks (ZOBECK

et al., 1986); $\mathrm{O}$ silt loam soil $-\mathrm{K}_{\text {sat }}$ measurements at the surface with double ring infiltrometers of different sizes (LAI \& REN, 2007)

An example of combining the pedotransfer with upscaling was recently presented by PACHEPSKY et al. (2014). A 4-month-long experiment was conducted at the USDA-ARS experimental site where $\mathrm{Cl}^{-}$was applied as a tracer with a pulse of irrigation water and its transport in groundwater and variably saturated shallow coarse-textured soils was monitored in two rows of wells on a daily basis. The HYDRUS-3D software (PC-PROGRESS, Prague) was used to set and calibrate the Richards model for flow simulations and the convective-dispersive equation for transport simulations. Saturated hydraulic conductivity values were estimated with class pedotransfer functions derived from the USDA database (RAWLS et al., 1998) containing results of about 1000 measurements in soils of different textures and bulk densities. A power law scaling for the saturated hydraulic conductivity was applied. When only two parameters of the scaling law rather than nine values of hydraulic conductivity from nine soil materials were calibrated, using the scaled saturated hydraulic conductivity values, resulted in an accuracy of simulations that was similar to the accuracy of the calibrated model results. Thus, scaling of pedotransfer-estimated saturated hydraulic conductivities can provide reasonable estimates for numerical flow and transport modeling in variably saturated soils. 
Pedotransfer at coarse scales

Scales coarser than the plot scale present unique challenges for pedotransfer research. These scales are societally important and therefore the scrutiny of results is different compared with small scales. Management becomes a factor and an efficient input, land use being an example. Often class inputs replace the continuous inputs. Accordingly, estimates based on classifications rather than on regressions become of interest, for example when input information of the PTF is of the categorical type, as in the case of soil maps (ТóTH et al., 2012) or soil survey information (LILLY et al., 2008).

An example of database analysis to build class-based pedotransfer functions was developed on 216 soil pedons for soils of moderate and large extent from the USDA Natural Resources Conservation Service (NRCS) soil characterization database (RAWLS \& PACHEPSKY, 2002). Textural classes, genetic horizon numbers, slopes, position on the slope classes, and land surface shape classes were the field descriptors to estimate water retention at -33 and $-1500 \mathrm{kPa}$ potentials for each horizon in each pedon. Because the input variables were both categorical and continuous, regression trees were used for subdividing the samples into the smallest number of the most homogeneous groups, which we tentatively called topotextural groups (TTG). Ten or fewer TTGs were defined for both the -33 and the $-1500 \mathrm{kPa}$ retention. The TTGs were different for the two matric potential levels. For the A horizon, the topotextural grouping resulted in estimates that were more accurate than those using laboratory textures only. Although most of the topographic variables were categorical in this work, those variables seemed to be useful for obtaining estimates of water retention.

One important reason to combine topographic and texture information to estimate water retention in field-, watershed-, and regional-scale projects is that soil textural classes are relatively broad, often only the dominating textural class is shown in soil maps, cartographers routinely use error-prone field judgments of soil texture, and soil texture is known to vary along slopes and to depend on the land surface shape.

Another scale-related matter is pedotransfer for coarse-scale soil modeling, for example, in weather or climate models. At coarse scales, parameterization of soil hydrology uses parameters other than (1) and (2), e.g. field capacity, thick layer conductance, etc. The specific of these parameters is that they cannot be measured and the efficiency of the pedotransfer can be evaluated only in terms of the landatmosphere model performance. There is a pressing need to determine combinations of pedotransfer and upscaling procedures that can lead to the derivation of suitable coarse-scale soil model parameters. The spatial coarse scale often assumes a coarse temporal support, and that may lead to including in PTFs other environmental variables such as topographic, weather, and management attributes. Adding land use categories to the list of inputs presents an interesting and very much underused avenue to explore. However, this approach faces difficulties, because land use information is lacking from most of the hydropedological datasets or the variability of land use types is not sufficient for the analysis. 


\section{Techniques to develop and evaluate PTFs}

There has been a substantial evolution in techniques used to relate inputs and outputs of pedotransfer relationships. Linear regressions were replaced with nonlinear regressions. Then k-nearest neighbor algorithms (e.g. NEMES et al., 2006; BOTULA et al., 2015), artificial neural networks (e.g. MINASNY et al., 1999), classification and regression trees (e.g. LILLY et al., 2008; MARTIN et al.,2009; TóTH et al., 2015), random forests (e.g. SEQUEIRA, 2014; TÓTH et al., 2014), support vector machines (e.g. LAMORSKI et al., 2008; HAGHVERDI et al., 2014), and Bayesian networks became popular (e.g. GHANBARIAN et al., 2015). The ensemble methodology was introduced, which relies on a number of simple, not very accurate models that appear to provide better predictors than raw soil basic property values. It includes a number of individual models and provides more robust predictions (BAKER \& ELISON, 2008). Each of these techniques has both advantages and disadvantages, some of which are characterized in MINASNY and HARTEMINK (2011).

Evaluation of PTFs is an essential element of their development and use. PACHEPSKY et al. (1999) broadly defined the accuracy of a PTF as the degree of correspondence between measured and estimated data for the data set from which the PTF was developed. The reliability of a PTF was assessed in terms of the correspondence between measured and estimated data for data set(s) other than the one used to develop the PTF. Finally, the utility of a PTF in modeling was viewed as the degree of correspondence between measured and simulated environmental variables.

The concept of PTF uncertainty (SCHAAP \& LEIJ, 1998) encompasses the ambiguity in PTF predictions and parameters caused by input data variability and uneven representation of soils with different properties in the database. The uncertainty in PTF estimates may be evaluated using replicated PTF development with data resampling by either the bootstrap (SCHAAP et al., 1998) or jackknife (PACHEPSKY \& RAWLS, 1999) methods. Another technique to reduce over-fitting of PTFs is using cross validation (MARTIN et al., 2009; LAMORSKI et al., 2014; TÓTH et al., 2015).

The reliability of a PTF is not directly related to its utility (PACHEPSKY et al., 1999). The latter is affected by the sensitivity of the model to PTF predictions, and also by the uncertainty in other model inputs (LEENHARDT, 1995). The functional evaluation of PTFs considers the evaluation of PTFs on the basis of their utility and uses criteria directly related to specific applications rather than statistics to characterize the accuracy. PTF accuracy may not be an issue since at least four factors affect the performance of a PTF in simulations. These are the accuracy of basic soil data used as inputs in the PTFs, the accuracy of the PTF itself, specific features of the simulation model, and the output used in the functional criteria (WÖSTEN \& VAN GENUCHTEN, 1988).

CHIRICO et al. (2010) found that PTF model error influences the uncertainty of hydrological models fed by the output of the PTFs to a greater extent, while input data error is less important. 


\section{Persistent knowledge gaps in pedotransfer developments}

Burgeoning PTF development has not so far affected several persisting regional knowledge gaps. Remarkably little effort was put so far into PTF development for saline soils (RAJKAI, 1988; TÓTH et al., 2012), calcareous (KHODAVERDILOO, 2011) and gypsiferous soils, peat soils, paddy soils (AIMRUN \& AMIN, 2009), soils with well-expressed shrink-swell behavior, and soils affected by freeze-thaw cycles. Soils from tropical regions are quite often considered as a pseudo-entity for which a single PTF can be applied (e.g. MINASNY \& HARTEMINK, 2011). This assumption will not be needed later, as more regional data is accumulated and analyzed. Other advances in regional PTFs may be possible due to the presence of large databases on region-specific useful PTF inputs such as moisture equivalent (Brazil), laser diffractometry data (Poland), or soil specific surface (Iran).

Seasonal changes in pedotransfer inputs and outputs may be substantial, especially in the topsoil. For example, WUEST (2015) reported up to $33 \%$ variation in soil bulk density in the topsoil during 39 months of observations. In most cases, more than one-third of the range in monthly means could be assigned to a seasonal component; that is, the means of a particular calendar month tended to be greater or less than the overall average. PACHEPSKY et al. (1992) saw more than $20 \%$ of seasonal variation in water retention. Ignoring the temporal dynamics of soil hydraulic properties creates several hurdles. First, the reliability of derived pedotransfer equations can be hindered by the mismatch in measurements of inputs and outputs. Second the utility of PTFs can be compromised by the mismatch in measurement times of hydraulic properties and soil water and/or flux time series. The magnitude of possible errors has never been assessed.

Spatial correlations in soil hydraulic properties are of special interest for interpolation purposes. So far no support was found for the hypothesis that spatial correlations in PTF-estimated and measured values are not significantly different (i.e. SINOWSKI et al., 1997). It remains to be learned whether this is a common situation and how this affects the accuracy of spatial mapping based on PTFs.

Pedotransfer is widely used to simulate overland flow, but the scale effects on overland flow model parameters have not been studied widely. In particular, it is not known whether scale effects are the reason for the mixed results achieved in the use of curve numbers. Hierarchically organized surface heterogeneities can speed preferential flow and transport up but they can also slow transport down (VAN DE GIESEN, 2011).

\section{Pedotransfer and grand challenges of the twenty-first century}

As instruments for packaging and dissemination of the soil information essential for environmental predictions and risk assessment, pedotransfer functions are increasingly in demand in research related to global change. In fact, pedotransfer functions are indispensable in utility in data-poor environments and large scale projects. 
A large role is played by PTFs in carbon stock assessments and carbon sequestration forecasts. Pedotransfer functions for bulk density are needed to convert gravimetric soil organic carbon contents into the volumetric values used in carbon accounting. SCHRUMPF et al. (2011) noted that the application of PTFs for the estimation of bulk densities caused considerable underestimation of total variances of OC stocks if the error associated with the PTF was not accounted for. Global estimates of soil nitrogen stock were obtained using pedotransfer relationships (GLENDINING et al., 2011). In this work, the most important predictor was found to be soil organic carbon (SOC). Other helpful soil and site properties for predicting $\mathrm{TN}$ included distance from the equator, soil texture class, soil group $\mathrm{C}: \mathrm{N}$ ratio, $\mathrm{pH}$, and \% clay. Modeling soil carbon stock evolution with the popular RothC model can rely on PTFs that provide an estimation of all active carbon pools. As independent variables, only total organic carbon (TOC) and clay content are used, which are easily available at most scales (WEIHERMUELLER et al., 2013). Soil aggregation as an essential factor of soil carbon change affected by future climate forcing has also been addressed in a pedotransfer context (KLOPFENSTEIN et al., 2015). Parameterization of the nitrate emission model DNDC with PTFs resulted in a clear improvement of the simulated variables at experimental sites in Belgium (BEHEYDT et al., 2007).

Climate change and related hydrological weather events impose the need for better parameterization of soil properties in weather and climate models at different scales. This translates into the need for selection, improvement, and evaluation of PTFs. BREUER et al. (2012) compared results of planetary boundary layer (PBL) height simulations obtained over the Carpathian Basin with soil hydraulic property estimates from two databases - the local, Hungarian HUNSODA (NEMES, 2002) and a database from the US (COSBY et al., 1984). Some soil hydraulic parameter values in the two datasets differed by $5 \%$ to $50 \%$. These differences resulted in $10 \%$ deviations in averaged PBL heights over Hungary and in differences up to $25 \%$ over smaller subareas. LIVNEH et al. (2015) noted that soil textural assumptions present an often overlooked source of hydrologic modelling uncertainty in hydrologic states and fluxes. Mesoscale hydrologic model simulations driven by the digital general soil map of the USA (STATSGO2) soil database (1:250000) were compared with those using the Food and Agriculture Organization (FAO)-based harmonized world soil database (1:5000000) over the Mississippi river basin.

Model simulations using STATSGO2 consistently led to greater separation between fast and slow runoff responses (by approximately 24-39\%) and, generally, more extreme responses to historic flood and drought events. The choice of soil database altered the partitioning of precipitation between evapotranspiration and runoff, and affected the correlation structure between forcing and modelled fluxes by up to 0.2 points. DE LANNOY (2015) pointed out that the advent of new data sets describing soil texture and associated soil properties offers the promise of improved hydrological simulations. The Catchment land surface model (LSM) of the NASA Goddard Earth Observing System version 5 (GEOS-5) was upgraded using new texture data, with hydraulic parameters derived for a more extensive set of texture classes using pedotransfer functions. 
A suite of simulations with the original and new parameter versions showed modest, yet significant improvements in the Catchment LSM's simulation of soil moisture and surface hydrological fluxes.

Deciphering changes in hydrological conditions and extreme events is of paramount importance as climate change manifestations become more profound.

MiLler et al. (2008) demonstrated the use of pedotransfer functions to accurately assign curve numbers in hydrologic models used for the design of flood hazard mitigation structures.

Contributions of the soil to the delivery of ecosystem services are manifold. CALZOLARI et al. (2016) researched the composition and interrelation of multiple soil functions and potential services based on soil functions as derived from available soil data for a reference depth of $100 \mathrm{~cm}$. The methodology included locally calibrated pedotransfer functions.

PALM et al. (2007) assumed that the natural capital of soils that underlies ecosystem services is primarily determined by three core soil properties: texture, mineralogy, and soil organic matter. They proposed an approach combining digital soil maps, pedotransfer functions, remote sensing, spectral analysis, and soil inference systems for the simultaneous characterization of various chemical, physical, and biological properties to overcome the great limitations and costs of conventional methods of soil assessments.

Overall, pedotransfer functions currently serve as integral and essential instruments in the science-based toolbox for diagnostics, monitoring, predictions, and management of the changing Earth. The interest in Earth observations results in the appearance of new observation products, survey methods, and data analysis techniques that also benefit PTF development and use.

\section{Conclusions}

Pedotransfer functions (PTFs) are empirical relationships between parameters of soil models and more easily obtainable data on soil properties. PTFs have become an indispensable tool in modeling soil processes. As alternative methods to direct measurements, they bridge the data we have and data we need by using soil survey and monitoring data to enable modeling for real-world applications. Pedotransfer is extensively used in soil models addressing the most pressing environmental issues. Some critical problems that are faced by PTF development and applications can be summarized as follows. As more intricate biogeochemical processes are being modeled, development of PTFs for parameters of those processes becomes essential. Emergence of a small number of well accepted models will be helpful and PTF development can be focused on the parameters of these models.

Since any generally suitable forms of equations to express PTF relationships are essentially unknown, there has been a trend to employ highly nonlinear models using so-called pattern recognition techniques, e.g. neural networks, decision trees, support vector machines, random forests, which in theory are flexible enough to simulate any dependence. This, however, comes with the penalty of a large number 
of coefficients that are difficult to estimate reliably and are usually more datahungry.

The multiplicity of models, i.e. presence of several models producing the same output variables, is commonly found in soil modeling, and is a typical feature in the PTF research field as well. However, PTF intercomparisons are lagging behind PTF development. This is aggravated by the fact that the coefficients of PTFs based on machine-learning methods are usually not reported.

Estimating the variability of soil model parameters becomes increasingly important, as newer modeling technologies such as data assimilation, ensemble modeling, and model abstraction, become progressively more popular. The variability of soil properties can be derived from the spatio-temporal dynamics of soil variables, and that opens new sources of PTF inputs stemming from technology advances such as monitoring networks, remote and proximal sensing, and omics.

PTF development has not so far affected several persisting regional knowledge gaps. Soils with specific hydraulic properties do not have reliable PTFs. Most flux models in soils, be it water, solutes, gas, or heat, involve parameters that are scaledependent. Including scale dependencies in PTFs will be critical to improve PTF usability. Another scale-related matter is pedotransfer for coarse-scale soil modeling, for example, in weather or climate models.

Some PTF inputs are time- or space-dependent, and yet little is known about whether the spatial or temporal structure of PTF outputs is properly predicted from such inputs.

Further exploration is needed to use PTFs as a source of hypotheses on and insights into relationships between soil processes and soil composition as well as between soil structure and soil functioning. Using models of soil-forming processes to generate PTFs, and in general, developing physics-based PTFs, remains to be explored. The use of geophysical data and soil proximal sensing data in PTFs will increase as the measurement techniques become available; physics-based interpretation of such PTFs is expected to be in demand.

The use of PTFs is prone to encounter the "sorcerer's apprentice" problem. Availability and ease of use may preclude proper PTF evaluation and PTF selection. An effort needs to be made to inform PTF users about limitations and pitfalls of using an arbitrary PTF "from the shelf".

PTFs are empirical relationships and their accuracy outside the database used for the PTF development is essentially unknown. Therefore, they should never be considered as an ultimate source of parameters in soil modeling. Rather, PTF developers strive to provide a balance between accuracy and availability. The primary role of PTF is to assist in modeling for screening and comparative purposes, establishing ranges and/or probability distributions of model parameters, and creating realistic synthetic soil datasets and scenarios. Developing and improving PTFs will remain the mainstream way of packaging data and knowledge for applications of soil modeling. 


\section{References}

Aimrun, W., \& Amin, M. S. M., 2009. Pedo-transfer function for saturated hydraulic conductivity of lowland paddy soils. Paddy and Water Environment. 7. (3) 217 225.

Arora, B., Mohanty, B. P. \& Mcguire, J. T., 2015. An integrated Markov chain Monte Carlo algorithm for upscaling hydrological and geochemical parameters from column to field scale. Science of the Total Environment. 512-513. 428-443.

Babaeian, E., Homaee, M., Montzka, C., Vereecken, H. \& Norouzi, A. A., 2015. Towards retrieving soil hydraulic properties by hyperspectral remote sensing. Vadose Zone Journal. 14. (3) doi: 10.2136/vzj2014.07.0080

BAKER, L., \& ELLISON, D., 2008. Optimisation of pedotransfer functions using an artificial neural network ensemble method. Geoderma. 144. (1-2) 212-224.

BATJES, N. H., 1996. Development of a world data set of soil water retention properties using pedotransfer rules. Geoderma. 71. 31-52.

Beheydt, D., Boeckx, P., Sleutel, S., Li, C., \& Van Cleemput, O., 2007. Validation of DNDC for 22 long-term $\mathrm{N}_{2} \mathrm{O}$ field emission measurements. Atmospheric Environment. 41. (29) 6196-6211.

Botula, Y.-D., Nemes, A., Van Ranst, E., Mafuka, P., De Pue, J., \& Cornelis, W. M., 2015. Hierarchical Pedotransfer Functions to Predict Bulk Density of Highly Weathered Soils in Central Africa. Soil Science Society of America Journal. 79. (2) 476-486.

Bouma, J. \& VAN LAnen, H. A. J., 1987. Transfer functions and threshold values: from soil characteristics to land qualities. In: Quantified Land Evaluation Procedures. (Eds.: Beck, K. J., Borrough, P. A. \& McCormack, D. E.) 106-110. Proc. Int. Workshop Washington. ITC Publication 6. Enschende.

BoumA, J., 1989. Using soil survey data for quantitative land evaluation. Advances in Soil Science. 9. 177.

Breuer, H., Ács. F., Laza, B., Horváth, Á., Matyasovszky, I., \& RajKai, K., 2012. Sensitivity of MM5 simulated planetary boundary layer height to soil dataset: comparison of soil and atmospheric effects. Theoretical and Applied Meteorology. 109. (3-4) 577-590.

Briggs, L. J. \& Shantz, H. L., 1912. The Wilting Coefficient and Its Indirect Determination. Botanical Gazette. 53. (1) 20-37

Brooks, R. H. \& Corey, A. T., 1964. Hydraulic Properties of Porous Media. Hydrological Paper No. 27. Colorado State University. Fort Collins.

Brutsaert, W., 1966. Probability laws for pore size distributions. Soil Science. 117. 311-314.

Calzolari, C., Ungaro, F., FilipPi, N., Guermandi, M., Malucelli, F., Marchi, N., \& TAROCCO, P., 2016. A methodological framework to assess the multiple contributions of soils to ecosystem services delivery at regional scale. Geoderma. 261. 190-203.

CARSEl, R. F., \& PARrish, R. S., 1988. Developing joint probability-distributions of soil-water retention characteristics. Water Resources Research. 24. (5) 755-769.

Carter, M. \& Bentley, S. P., 1991. Correlations of Soil Properties. Pentech Press. London. 
Chirico, G., B., Medina, H., \& Romano, N., 2010. Functional evaluation of PTF prediction uncertainty: An application at hillslope scale. Geoderma. 155. 193-202.

Cichota, R., Vogeler, I., SnOw, V. O., \& WeBB, T. H., 2013. Ensemble pedotransfer functions to derive hydraulic properties for New Zealand soils. Soil Research. 51. 94-111.

Cosby, B. J., Hornberger, G. M., Clapp, R. B., \& Ginn, T. R., 1984. A statistical exploration of the relationships of soil moisture characteristics to the physical properties of soils. Water Resources Research. 20. (6 ) 682-690.

Dai, Y., Shangguan, W., DuAn, Q., LiU, B., Fu, S., \& NiU, G., 2013. Development of a China Dataset of Soil Hydraulic Parameters Using Pedotransfer Functions for Land Surface Modeling. Journal of Hydrometeorology. 14. 869-887.

Daroussin, J. \& KinG, D., 1996. Pedotransfer rules database to interpret the Soil Geographical Database of Europe for environmental purposes. In: Proc. of the Workshop on the Use of Pedotransfer in Soil Hydrology Research in Europe. (Eds.: Bruand, A., Duval, O., Wösten, H. \& Lilly, A.) 25-40. Orleans, France.

De Lannoy, G. J. M., Koster, R. D., Reichle, R. H., Mahanama, S. P. P., \& LiU, Q., 2015. An updated treatment of soil texture and associated hydraulic properties in a global land modeling system. Journal of Advances in Modeling Earth Systems. 6. (4) 957-979.

Deng, H., Ye, M., SchaAp, M. G., \& Khaleel, R., 2009. Quantification of uncertainty in pedotransfer function-based parameter estimation for unsaturated flow modeling. Water Resources Research. 45. (4) Doi: 10.1029/2008WR007477

FAUlKNER, B. R., LyOn,,W..G., KHAN, F.A. \& ChATTOPADHYAY, S., 2003. Modeling leaching of viruses by the Monte Carlo method. Water Research. 37. (2003) 47194729.

Ghanbarian, B., Taslimitehrani, V., Dong, G., \& Pachepsky, Ya. A., 2015. Sample dimensions effect on prediction of soil water retention curve and saturated hydraulic conductivity. Journal of Hydrology. 528. 127-137.

Glendining, M. J., Dailey, A. G., Powlson, D. S., Richter, G. M., CAtt, J. A., \& Whitmore, A. P., 2011. Pedotransfer functions for estimating total soil nitrogen up to the global scale. European Journal of Soil Science. 62. (1) 13-22.

Guber, A. K., Pachepsky, Ya. A., Van Genuchten, M. Th., Rawls, W. J., Jacques, D., SimuneK, J., CADY, R. E., \& Nicholson, T. J., 2005. Field-scale water flow simulations using ensembles of pedotransfer functions for soil water retention. Vadose Zone Journal. 5. 234-247.

Guber, A. K., Pachepsky, Y. A., Van Genuchten, M. Th., SimuneK, J., Jacques, D., Nemes, A., Nicholson, T. J., \& CADY, R. E., 2009. Multimodel simulation of water flow in a field soil using pedotransfer functions. Vadose Zone Journal. 8. (1) 110.

Haghverdi, A., Cornelis, W. M., \& Ghahraman, B., 2012. A pseudo-continuous neural network approach for developing water retention pedotransfer functions with limited data. Journal of Hydrology. 442-443. 46-54.

HaghVERDI, A., ÖzTÜRK, H. S., \& CORNELIS, W. M., 2014. Revisiting the pseudo continuous pedotransfer function concept: Impact of data quality and data mining method. Geoderma. 226-227. 31-38. 
Khodaverdiloo, H., Homaee, M., Van Genuchten, M. Th., \& Dashtaki, S. G., 2011. Deriving and validating pedotransfer functions for some calcareous soils. Journal of Hydrology. 399. (1-2) 93-99.

Klopfenstein, S. T., Hirmas, D. R., \& Johnson, W. C., 2015. Relationships between soil organic carbon and precipitation along a climosequence in loess derived soils of the Central Great Plains, USA. Catena. 133. 25-34.

Kool, J. B., Albrecht, K. A., PArker, J. C. \& BAKer. C., 1986. Physical and chemical characterization of the Groseclose soil mapping unit. Bull. 86-4. Blacksburg, Va.: Virginia Agric. Exp. Sta., Virginia Polytechnic Institute and State Univ.

LAI, J., \& REN, L., 2007. Assessing the size dependency of measured hydraulic conductivity using double-ring infiltrometers and numerical simulation. Soil Science Society of America Journal. 71. (6) 1667-1675.

LAMORSKi, K., PACHePSKY, Ya., SŁAwiŃski, C., \& WAlCZAK, R. T., 2008. Using support vector machines to develop pedotransfer functions for water retention of soils in Poland. Soil Science Society of America Journal. 72. (5) 1243-1247.

Lamorski, K., SŁawiński, C., Moreno, F., Barna, G., Skierucha, W., \& Arrue, J. L., 2014. Modelling soil water retention using support vector machines with genetic algorithm optimisation. The Scientific World Journal. 2014. 740521.

LEENHARDT, D., 1995. Errors in the estimation of soil water properties and their propagation through a hydrological model. Land Use Manage. 11. (1995) 15-21.

LeiJ, F. J., Alves, W. J., van Genuchten, M. Th. \& Williams, J. R. 1996. The UNSODA unsaturated soil hydraulic database. User's manual version 1.0. National Risk Management Research Laboratory, Office of Research and Development, US Environmental Protection Agency. 103.

LiAO, K., XUA, F., Zheng, J., ZHU, Q., \& YANG, G., 2014. Using different multimodel ensemble approaches to simulate soil moisture in a forest site with six traditional pedotransfer functions. Environmental Modelling and Software. 57. 27-32.

Lilly, A., Nemes, A., Rawls, W. J., \& PAchepsky, YA. A., 2008. Probabilistic approach to the identification of input variables to estimate hydraulic conductivity. Soil Science Society of America Journal. 72. (1) 16-24.

LivNeH, B., KumAR, R. \& SAMANIEGO, L., 2015. Influence of soil textural properties on hydrologic fluxes in the Mississippi river basin. Hydrol. Process. 29. (21) 4638 4655.

Makó, A., Tóth, B., Hernádi, H., FARKAS, C., \& MARTh, P., 2010. Introduction of the Hungarian detailed soil hydrophysical database (MARTHA) and its use to test external pedotransfer functions. Agrokémia és Talajtan. 59. (1) 29-38.

Martin, M. P., Lo Seen, D., Boulonne, L., Jolivet, C., Nair, K. M., Bourgeon, G., \& ARROUAYS, D. 2009. Optimizing pedotransfer functions for estimating soil bulk density using boosted regression trees. Soil Science Society of America Journal. 73. (2) 485-493.

Martinez, G., Pachepsky, Ya. A., Vereecken, H., Hardelauf, H., Herbst, M., \& VANDERLINDEN, K., 2013. Modeling local control effects on the temporal stability of soil water content. Journal of Hydrology. 481. 106-118.

Martinez, G., Vanderlinden, K., Pachepsky, Ya., Cervera, J. V. G., \& Pérez, A. J. E., 2012. Estimating topsoil water content of clay soils with data from time-lapse electrical conductivity surveys. Soil Science. 177. (6) 369-376. 
McBratney, A. B., Minasmy, B., Cattle, S. R., \& Vervoort, R. W., 2002. From pedotransfer functions to soil inference systems. Geoderma. 109. (12) 41-73.

Miller, J., Caldwell, T., Young, M., \& Dalldorf, G., 2008 Verifying curve numbers in arid environments by combining detailed geomorphic mapping and pedotransfer functions. World Environmental and Water Resources Congress. 2008. 1-10. doi: 10.1061/40976(316)342.

Minasny, B., \& HARTEMINK, A. E., 2011. Predicting soil properties in the tropics. Earth-Science Reviews. 106. (1-2) 52-62.

Minasny, B., McBratney, A. B. \& Bristow, K. L., 1999. Comparison of different approaches to the development of pedotransfer functions for water-retention curves. Geoderma. 93. 225-253.

MuAlem, Y., 1976. A new model for predicting the hydraulic conductivity of unsaturated porous media. Water Resources Research. 12. 513-522.

NEMES, A., 2002. Unsaturated soil hydraulic database of Hungary: HUNSODA. Multiscale hydraulic pedotransfer functions for Hungarian soils.

Nemes, A., QuebedeAux, B., \& Timlin, D. J., 2010. Ensemble approach to provide uncertainty estimates of soil bulk density. Soil Science Society of America Journal. 74. (6) 1938-1945.

Nemes, A., RAWLS, W. J., \& PACHEPSKY, YA. A., 2006. Use of k-nearest neighbor algorithms to estimate soil hydraulic properties. Soil Science Society of America Journal. 70. 327.

Nemes, A., SchaAp, M. G., LeiJ, F. J., \& Wösten, J. H. M., 2001. Description of the unsaturated soil hydraulic database UNSODA version 2.0. Journal of Hydrology. 251. (34) 151-162.

NeUman, S. P., \& WierengA, P., 2003. A comprehensive strategy of hydrogeologic modeling and uncertainty analysis for nuclear facilities and sites. NUREG/CR6805. U.S. Nuclear Regulatory Commission. Washington, DC. Available at: http:/www.nrc.gov/reading-rm/doc-collections/nuregs/contract/cr6805/

PACHEPSKY, YA. A. \& RAWLS, W. J. (eds.), 2004. Development of Pedotransfer Functions in Soil Hydrology. Developments in Soil Science. 30. Elsevier. Amsterdam.

PAChePsKy, YA., Gish, T., Guber, A. K., YAKIREVICH, A. M., KuZnetsov, M. K., van Genuchten, M. T., Nicholson, T. J., \& CADY, R. E., 2011. Application of model abstraction techniques to simulate transport in soils. NUREG/CR-7026. U. S. Nuclear Regulatory Commission. Washington, D.C. 252. 2011. Available at http://www.nrc.gov/reading-rm/doc-collections/nuregs/contract/cr7026/

Pachepsky, Ya. A., Guber, A. K., Yakirevich, A. M., Mckee, L., Cady, R. E., \& NiCHOLSON, T. J., 2014. Scaling and pedotransfer in numerical simulations of flow and transport in soils. Vadose Zone Journal. 13. (12) doi:10.2136/vzj2014.02.0020

PACHEPSKY, YA. A., \& RAWLS, W. J., 1999. Accuracy and reliability of pedotransfer functions as affected by grouping soils. Soil Science Society of America Journal. 63. 1748-1757.

Pachepsky, Ya. A., Mironenko, E. V., \& Shcherbakov, R. A., 1992. Prediction and use of soil hydraulic properties. In: Indirect Methods for Estimating the Hydraulic Properties of Unsaturated Soils. (Eds.: VAN Genuchten, M. TH, LeIJ, F. J., \& LUND, L. J.) 203-212. Proceedings of the International Workshop. October, 11-13, 1989. University of California. Riverside. 
Pachepsky, YA. A., Rawls, W. J., \& Timlin, D. J., 1999. The current status of pedotransfer functions: their accuracy, reliability, and utility in field- and regionalscale modeling, In: Assessment of Non-Point Source Pollution in the Vadose Zone. (Eds.: Corwin, D. L., LOAGUE, K. \& Ellsworth, T. R.) 223-234. Geophysical Monograph 108. American Geophysical Union. Washington, D. C.

Palm, C., SAnchez, P., Ahamed, S., \& Awiti, A., 2007. Soils: A contemporary perspective. Annual Review of Environment and Resources. 32. 99-129.

Pan, F., Pachepsky, Ya., Jacques, D., Guber, A., \& Hill, R. L., 2012. Data assimilation with soil water content sensors and pedotransfer functions in soil water flow modeling. Soil Science Society of America Journal. 76. (3) 829-844.

Qu, W., Bogena, H. R., Huisman, J. A., Martinez, G., Pachepsky, Ya. A, \& VEREECKEN, H., 2014. Effects of soil hydraulic properties on the spatial variability of soil water content: evidence from sensor network data and inverse modeling Vadose Zone Journal. 13. (12) 112. doi: 10.2136/vzj2014.07.0099

Qu, W., Bogena, H. R., Huisman, J. A., Vanderborght, J., SchuH, M., Priesack, E., \& VereECKEN, H., 2015. Predicting subgrid variability of soil water content from basic soil information Geophysical Research Letters. 42. (3) 789796. doi: 10.1002/2014GL062496

RAJKAI, K., 1988. The relationship between water retention and different soil properties (in Hungarian). Agrokémia és Talajtan. 36-37. 15-30.)

RAWls, W. J., BRAKENSIEK, D. L., \& SAXTON, K. E., 1982. Estimation of soil-water properties. Transactions of the ASAE. 25. (5) 1316-1328.

RAWLS, W. J., GISH, T. J., \& BRAKENSIEK, D. L., 1991. Estimating soil water retention from soil physical properties and characteristics. Advances in Soil Science. 16. 213.

RAWLS, W.J., Gimenez, D., \& GROSSMAn, R., 1998. Use of soil texture, bulk density, and slope of the water retention curve to predict saturated hydraulic conductivity. Transactions of the ASAE. 41. 983-988.

RAWLS, W. J., \& PACHEPSKY, Y. A., 2002. Using field topographic descriptors to estimate soil water retention. Soil Science. 167. (7) 423-435.

Rawls, W. J., Nemes, A., Pachepsky, Ya. A., \& Saxton, K. E., 2007. Using the NRCS National Soils Information System (NASIS) to provide soil hydraulic properties for engineering applications. Transactions of the ASAE. 50.(5) 1715-1718.

SchaAp, M. G., LeiJ, F. J., \& VAN Genuchten, M. Th., 2001. Rosetta: A computer program for estimating soil hydraulic parameters with hierarchical pedotransfer functions. Journal of Hydrology. 251. (3-4) 163-176.

SchaAP, M. G., LeiJ, F. J., \& VAN GenUChTEN, M. TH., 1998. Neural network analysis for hierarchical prediction of soil hydraulic properties. Soil Science Society of America Journal. 62. (4) 847-855.

SchrumpF, M., Schulze, E. D., KAISER, K., \& SchumaCher, J., 2011. How accurately can soil organic carbon stocks and stock changes be quantified by soil inventories? Biogeosciences Discussions. 8. (1) 723-769.

Sequeira, C. H., Wills, S. A., Seybold, C. A., \& West, L. T., 2014. Predicting soil bulk density for incomplete databases. Geoderma. 213. 64-73.

SinOwski, W., Scheinost, A. C., \& Auerswald, K., 1997. Regionalization of soil water retention curves in a highly variable soilscape, II. Comparison of regionalization procedures using a pedotransfer function Geoderma. 78. (3-4) 145-159. 
Timlin, D. J., Ahuja, L. R., \& Williams, R. D., 1996. Methods to estimate soil hydraulic parameters for regional scale applications of mechanistic models, In: Application of GIS to the Modeling of Non-Point Source Pollutants in the Vadose Zone. American Society of Agronomy. SSSA Special publication. Madison. 185-203.

Timlin, D. J., Ahuja, L. R., Pachepsky, Y., Williams, R. D., Gimenez, D., \& Rawls, W., 1999. Use of BrooksCorey parameters to improve estimates of saturated conductivity from effective porosity. Soil Science Society of America Journal. 63. (5) 10861092.

Tóth, B., Makó, A., GuAdagnini, A., \& TóTh, G., 2012. Water retention of salt affected soils: quantitative estimation using soil survey information. Arid Land Research and Management. 26. 103-121.

Tо́тн, В., МАкÓ, А., \& Tо́тн, G., 2014. Role of soil properties in water retention characteristics of main Hungarian soil types. Journal of Central European Agriculture. 15. (2) 137-153.

Tóth, B., Weynants, M., Nemes, A., Makó, A., Bilas, G. \& Tóth, G., 2015. New generation of hydraulic pedotransfer functions for Europe. European Journal of Soil Science. 66. 226-238.

UGBAJe, S. U., \& REUTER, H. I., 2013. Functional digital soil mapping for the prediction of available water capacity in Nigeria using legacy data. Vadose Zone Journal. 12. doi:10.2136/vzj2013.07.0140.

Van De Giesen, N., Stomph, T., Ajayi, E. A., \& Bagayoko, F., 2011. Scale effects in hortonian surface runoff on agricultural slopes in West Africa: field data and models. Agriculture, Ecosystems \& Environment. 142. (1-2) 95-101.

VAN Genuchten, M. TH., 1980. Closed-form equation for predicting the hydraulic conductivity of unsaturated soils. Soil Science Society of America Journal. 44. 892-898.

VAn Genuchten, M. TH., \& LeiJ, F., 1992. On estimating the hydraulic properties of unsaturated soils. In: Indirect Methods for Estimating the Hydraulic Properties of Unsaturated Soils. (Eds.: VAN GENUCHTEN, M. T., LEIJ, F. J., AND LUND, L. J.) 114. University of California. Riverside.

VePRASKAS, M. J., \& Williams, J. P., 1995. Hydraulic conductivity of saprolite as a function of sample dimensions and measurement technique. Soil Science Society of America Journal. 59. 975-981

VereECKEN, H., MAES, J., \& FeYEN, J., 1990. Estimating unsaturated hydraulic conductivity from easily measured soil properties. Soil Science. 149. (1) 112.

Vereecken, H., MAes, J., FeYen, J., \& DARIUS, P., 1989. Estimating the soil moisture retention characteristic from texture, bulk density, and carbon content. Soil Science. 148. (6) $389-403$.

WANG, X., Yen, H., JeOnG, J., \& Williams, J. R., 2015. Accounting for conceptual soil erosion and sediment yield modeling uncertainty in the APEX model using Bayesian model averaging. Journal of Hydrologic Engineering. 20. (6) art. no. C4014010

Weihermueller, L., Graf, A., Herbst, M., \& Vereecken, H., 2013. Simple pedotransfer functions to initialize reactive carbon pools of the RothC model. European Journal of Soil Science. 64. (5) 567-575.

Werban, U., Dietrich, P., Bartholomeus, H., Grandjean, G., \& Zacharias, S., 2013. Digital soil mapping: Approaches to integrate sensing techniques to the prediction of key soil properties. Vadose Zone J. 12. doi:10.2136/vzj2013.10.0178. 
Weynants, M., Montanarella, L., Tóth, G., et al., 2013. European HYdropedological Data Inventory (EU-HYDI). Luxembourg: EUR - Scientific and Technical Research Series - ISSN 1831-9424, doi: 10.2788/5936.

Wösten, J. H. M., \& VAN GenUChten, M. TH., 1988. Using texture and other soil properties to predict the unsaturated soil hydraulic functions. Soil Science Society of America Journal. 52. (6) 1762-1770.

Wösten, J. H. M., PAChePSKY, YA. A. \& RAwls, W. J., 2001. Pedotransfer functions: bridging the gap between available basic soil data and missing soil hydraulic characteristics. Journal of Hydrology. 251. 123-150.

Wösten, J. H. M., Lilly, A., Nemes, A., \& Le BAS, C., 1999. Development and use of a database of hydraulic properties of European soils. Geoderma. 90. 169-185.

WuEST, S. B., 2015. Seasonal variation in soil bulk density, organic nitrogen, available phosphorus, and pH. Soil Science Society of America Journal., 79. (4) 1188-1197.

Zobeck, T. M., FAuSEY, N. R., \& Al-HAMDEN, N. S., 1985. Effect of sample crosssection area on saturated hydraulic conductivity in two structured soils. Transactions of the ASAE. 28. (3) 791-794. 